\title{
Produtividade da biomassa de melissa em função de intervalo de cortes e doses de nitrogênio
}

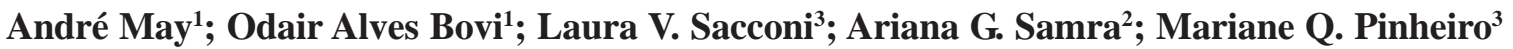 \\ ${ }^{1}$ Instituto Agronômico Campinas, C. Postal 28, 13012-970, Campinas-SP; ${ }^{2}$ Estagiária IAC; ${ }^{3}$ Bolsista PIBIC-CNPQ; \\ amay@iac.sp.gov.br;
}

\section{RESUMO}

A espécie Melissa officinalis tem crescido em importância econômica no setor produtivo de plantas medicinais, contudo o nível de informações agronômicas a cerca da espécie é limitado. Dessa forma, foi instalado um experimento visando avaliar a influência do intervalo de cortes e de doses de nitrogênio sobre a produção de biomassa dessa espécie. O delineamento experimental utilizado foi o de blocos ao acaso, com três repetições, em esquema fatorial 4 x 4 , sendo os fatores estudados o intervalo de cortes $(30 ; 42 ; 54$ e 66 dias) e dose de nitrogênio (0; 60; 120 e $180 \mathrm{~kg} \mathrm{ha}^{-1}$ de N). Foram avaliadas a altura da planta e massa seca da parte aérea. Observouse maior altura da planta para maior intervalo entre corte. Maiores rendimentos de massa seca foram observados com a aplicação de $180 \mathrm{~kg} \mathrm{ha}^{-1}$ de $\mathrm{N}$, havendo uma resposta linear para a produção de massa seca com a aplicação de $\mathrm{N}$.

Palavras-chave: Melissa officinalis, manejo cultural, nutrição.

\begin{abstract}
Biomass production of Lemon balm as a result of cutting interval and nitrogen levels

Cultivation of Melissa officinalis is increasing in economic importance in the market of medicinal plants, although the level of agronomic information concerning the specie is limited. To achieve those objectives, a trial was carried out to study the influence of cutting intervals and nitrogen levels in biomass production. The experimental design was in blocks with three replications in a $4 \mathrm{x} 4$ factorial cheme: cutting intervals (30; 42; 54 and 66 days) and nitrogen $(0 ; 60 ; 120$ and $180 \mathrm{~kg} \mathrm{ha}^{-1}$ of $\mathrm{N}$ ). The characteristics of plant height and aerial part and accumulated dry mater were evaluated. Increasing the cutting intervals resulted in higher plants. The highest dry matter value was observed using $180 \mathrm{~kg} \mathrm{ha}^{-1}$ of $\mathrm{N}$, having a linear reply for the production of dry mass with the application of $\mathrm{N}$.
\end{abstract}

Keywords: Melissa officinalis, cultural management, nutrition.

\section{(Recebido para publicação em 14 de janeiro de 2007; aceito em 23 de junho de 2008)}

A melissa (Melissa officinalis L.) é uma planta pertencente à família Lamiaceae, sendo originária da Ásia (Montanari Júnior, 1999). Sartório et al. (2000) indicam diversos usos para a planta de melissa, como por exemplo: crises nervosas, taquicardia nervosa, melancolia, histerismo e ansiedade.

A planta fresca tem cerca de 0,02 a $0,2 \%$ de óleos essenciais, cujos principais componentes são o citral a e b, e o citronelal, além de metilcitronelal, citronelol, nerol e geraniol. É bastante utilizada para a produção de cosméticos como xampus, sabonetes, cremes faciais, etc. Na indústria alimentícia é muito utilizada na preparação de licores e como antioxidante (Montanari Júnior, 1999).

Vömel (1984) cita que as plantas utilizadas para fins terapêuticos necessitam de fertilizações minerais que devem ser feita adequadamente e em níveis previamente estudados, para maior produção de princípios ativos.

O rendimento e a composição dos óleos essenciais das plantas são influenciados por diversos fatores, sendo os mais importantes a parte da planta utili- zada para a extração do óleo, idade da planta, época de colheita, condições ambientais e fertilizações (Corrêa Júnior et al., 1994).

Maia (1998) informa que para a Mentha arvensis L., da mesma família da Melissa officinalis L., o nitrogênio proporciona resposta positiva sobre a produção de massa seca, e cita que alguns autores têm encontrado respostas positivas do nutriente mesmo em altas doses (150 kg ha-1 de N).

Dentre os fatores que interferem na composição química da planta, a nutrição certamente é um dos mais importantes. O nitrogênio tem ações muito variáveis nas plantas, afetando de diferentes formas os teores de óleos essenciais nas plantas medicinais e aromáticas, havendo respostas variáveis conforme a espécie, condições ambientais (fotoperíodo, umidade do solo e temperatura) e os tratos culturais (Martins et al., 1993).

O manejo da cultura é determinante na produção de folhas e óleo essencial. Czepak (1995) estudou a influência do intervalo de cortes em Mentha arvensis L. O autor verificou que colheitas rea- lizadas a cada 60, 70 e 90 dias após o plantio proporcionaram maior volume de óleo ao longo de um ano de colheitas. No entanto, houve tendência de acamamento das plantas nos intervalos mais longos entre cortes.

Blank et al. (2005) citam que, em cultivos comerciais de Melissa officinalis em Sergipe, é feito o replantio da cultura após o primeiro corte devido à alta taxa de mortalidade de plantas nas condições climáticas do Nordeste brasileiro.

Hernández et al. (2001), estudando Melissa officinalis, encontraram produtividades de massa seca da parte aérea acumulada de $5,7 \mathrm{t} \mathrm{ha}^{-1}\left(30,9 \mathrm{t} \mathrm{ha}^{-1} \mathrm{de}\right.$ massa fresca), com 4 cortes ao ano, com aplicação de $108 \mathrm{~kg} \mathrm{ha}^{-1}$ de N, aplicados a cada corte.

Neste trabalho objetivou-se avaliar a influência do intervalo de cortes e de doses de nitrogênio sobre a produção de biomassa de melissa.

\section{MATERIAL E MÉTODOS}

O experimento foi conduzido de maio/ 05 a maio/06, no município de Campinas- 
SP, nas instalações do Centro de Horticultura do Instituto Agronômico.

O delineamento experimental utilizado foi de blocos ao acaso, com três repetições, em esquema fatorial 4 × 4 , sendo os fatores estudados o intervalo de cortes $(30 ; 42 ; 54$ e 66 dias) e dose de nitrogênio $\left(0 ; 60 ; 120\right.$ e $180 \mathrm{~kg} \mathrm{ha}^{-1}$ de N).

Para a formação das mudas foram utilizadas estacas herbáceas com $8 \mathrm{~cm}$ de comprimento, contendo apenas 2 folhas desenvolvidas e o meristema apical intacto oriundas da coleção de plantas aromáticas do Instituto Agronômico. As estacas preparadas foram plantadas em bandejas de isopor de 200 células, contendo substrato Plantmax ${ }^{\circledR}$ para folhosas.

As mudas foram transplantadas quando estavam com 5 a 6 folhas desenvolvidas para um telado com malha de sombreamento de $50 \%$.

A análise do solo do local da experimentação, coletado na profundidade de 0,2 m, revelou: $\mathrm{pH}$ em $\mathrm{CaCl}_{2}$ de 4,4 e 28 $\mathrm{g} \mathrm{dm}^{-3}$ de matéria orgânica, além de 22 $\mathrm{mg} \mathrm{dm}{ }^{-3}$ de P-resina. Os teores de $\mathrm{K}, \mathrm{Ca}$, $\mathrm{Mg}, \mathrm{H}+\mathrm{Al}$ foram, respectivamente, 1,0 ; 14; 6 e $64 \mathrm{mmol}_{\mathrm{c} .} \mathrm{dm}^{-3}$ e a CTC efetiva igual a 85,4 mmol $\mathrm{dm}^{-3}$, segundo metodologia descrita por Raij et al. (2001).

As parcelas eram compostas de cinco linhas de 2 metros de comprimento espaçadas de 0,3 m. O espaçamento entre plantas foi de $0,2 \mathrm{~m}$. A parcela útil, em que foram coletadas as informações sobre as características avaliadas, foi constituída pelas três linhas internas da parcela, excluindo-se primeira e última planta de cada linha, totalizando 24 plantas úteis por parcela.

Para o fornecimento de N, P e K, foram utilizados o nitrato de amônio, superfosfato simples e cloreto de potássio, respectivamente. Todo o fósforo foi aplicado no sulco antes do transplantio das mudas (100 $\left.\mathrm{kg} \mathrm{ha}^{-1} \mathrm{de} \mathrm{P}\right)$, juntamente com $180 \mathrm{~kg} \mathrm{ha}^{-1}$ de K (Montanari Júnior, 1999) e $15 \mathrm{~kg} \mathrm{ha}^{-1} \mathrm{de} \mathrm{N}$, sendo levemente incorporadas com o auxílio de enxada, exceto para a testemunha que não recebeu este nutriente. As doses de nitrogênio foram aplicadas à lanço, após cada corte, ou seja, a quantidade total de nitrogênio em cada tratamento foi dividi-

Tabela 1. Valores médios de massa seca acumulada da parte aérea (Massa Seca) em função do intervalo de cortes estudado. (mean values of aerial part dry matter accumulated as a function of interval between cuts). Campinas, IAC, 2006.

\begin{tabular}{cc}
\hline Intervalo de cortes (dias) & Massa Seca $\left(\mathbf{k g ~ h a} \mathbf{~}^{-1}\right)$ \\
\hline 30 & $2420 \mathrm{a}$ \\
42 & $1980 \mathrm{a}$ \\
54 & $2140 \mathrm{a}$ \\
66 & $2000 \mathrm{a}$ \\
\hline d.m.s. & 685 \\
CV (\%) & 28,8741 \\
\hline
\end{tabular}

Médias seguidas de letra iguais são estatisticamente semelhantes entre si, ao nível de 5\% de probabilidade pelo Teste de Tukey.

da pelo total de cortes realizados em cada parcela durante o período de experimentação $(10 ; 7 ; 6$ e 4 cortes, respectivamente para os intervalos entre cortes de 30; 42; 54 e 66 dias). Da quantidade de $\mathrm{N}$ em cobertura foi descontada a aplicação de $15 \mathrm{~kg} \mathrm{ha}^{-1}$ de $\mathrm{N}$ no plantio. A calagem foi feita para elevar a $70 \%$ a saturação por bases.

As plantas foram irrigadas por aspersão convencional, semanal, com uma lâmina de $10 \mathrm{~mm}$ por irrigação.

$\mathrm{O}$ primeiro corte foi feito aos 50 dias após o transplantio das mudas para o campo. A partir de então, foi estabelecido o fator "Intervalo de cortes". A operação de corte foi manual, realizada com o auxílio de uma foice de mão. O corte foi realizado a $10 \mathrm{~cm}$ do solo em todos os tratamentos.

Foram avaliadas a altura da planta (distância entre o nível do solo e a extremidade superior da planta, em $\mathrm{cm}$ ), massa seca da parte aérea e rendimento de óleo essencial na massa fresca.

Foram feitas destilações de $150 \mathrm{~g}$ de parte aérea total da planta fresca em cada tratamento em cada data de corte, em destilador Clevenger modificado pelo período de 2 horas. A secagem da parte aérea foi feita em estufas de circulação forçada de ar quente a $65^{\circ} \mathrm{C}$, para a obtenção da massa seca.

Para estudo da influência dos fatores na produção de massa seca, foi feito o somatório da massa seca da parte aérea ao longo do ciclo da cultura em cada tratamento, segundo o intervalo de cortes estabelecido, resultando na massa seca acumulada, expressada em $\mathrm{kg} \mathrm{ha}^{-1}$.

Os resultados foram submetidos à análise de variância e as médias dos tratamentos foram comparadas entre si pelo teste de Tukey ao nível de 5\% de probabilidade. Os dados obtidos foram ajustados por regressões polinomiais feitas com auxílio do programa ESTAT (UNESP-FCAV).

\section{RESULTADOS E DISCUSSÃO}

Não houve interação significativa entre os fatores intervalo de cortes e doses de nitrogênio para nenhuma das características avaliadas. Apenas houve efeito significativo isolado do fator intervalo de cortes para a altura da planta e do fator dose de nitrogênio sobre a massa seca acumulada da parte aérea.

Não houve diferença estatística entre as médias de massa seca acumulada da parte aérea em função do intervalo de cortes estudado (Tabela 1), provavelmente devido a um efeito compensatório das plantas, ou seja, houve um incremento na massa seca por corte quanto maior foi o intervalo de cortes empregado, conforme se observa pela divisão das médias de massa seca acumulada pelo número de cortes realizados, apresentando os valores 242; 283; 357 e $500 \mathrm{~kg} \mathrm{ha}^{-1}$ de massa seca por corte, representando, respectivamente, por 10; 7; 6 e 4 cortes ao longo do período experimental, referente a 30; 42; 54 e 66 dias entre cortes, respectivamente.

Os resultados médios da altura da planta foram ajustados em uma equação polinomial linear. Observaram-se maiores alturas de plantas para maiores intervalos de cortes (66 dias), 22,87 cm (Figura 1), mas sem alteração na massa seca da parte aérea acumulada. Contudo, as maiores massas secas por corte quanto maior o intervalo de cortes podem ser explicados pelo aumento da altura das plantas nos tratamentos com cortes a cada 66 dias. 


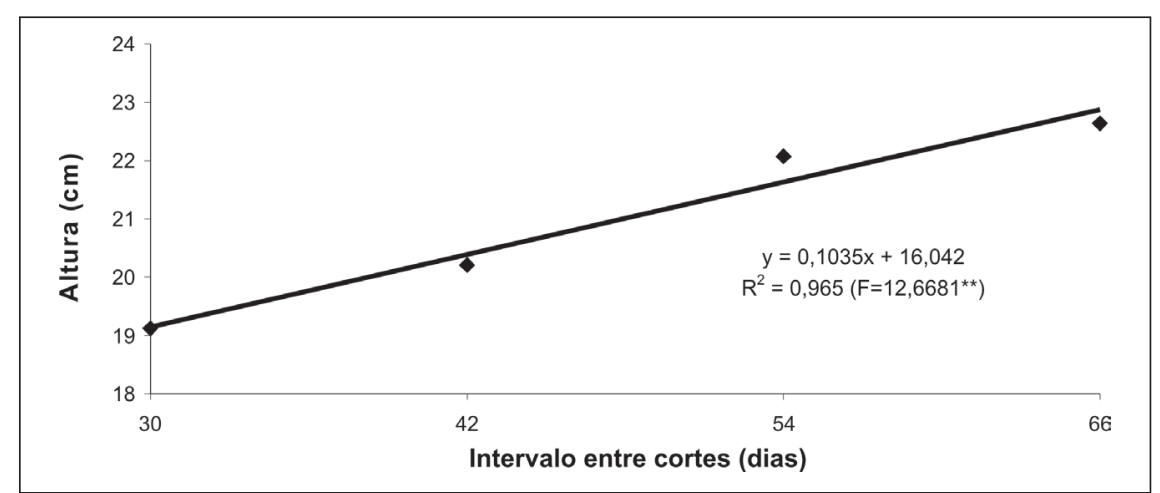

Figura 1. Altura da planta $(\mathrm{cm})$ em função do intervalo de cortes. (plant height as a function of interval between cuts). Campinas, IAC, 2006.

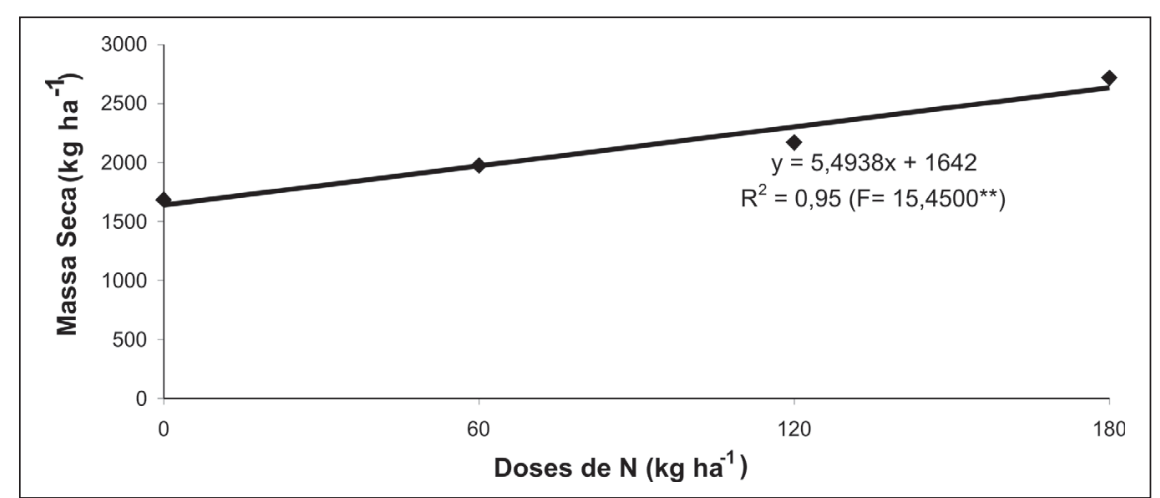

Figura 2. Acúmulo de massa seca da parte aérea (MSPA) em função de doses de nitrogênio. (aerial part accumulated dry matter as a function of applied nitrogen). Campinas, IAC, 2006.

A massa seca acumulada da parte aérea foi afetada apenas pela fertilização nitrogenada. Maiores rendimentos de massa seca foram observados com a aplicação de $180 \mathrm{~kg} \mathrm{ha}^{-1}$ de $\mathrm{N}\left(2,63 \mathrm{t} \mathrm{ha}^{-1}\right.$ de massa seca da planta toda, 23,7 g plan$\left.\mathrm{ta}^{-1}\right)$, havendo uma resposta linear para a produção de massa seca com a aplicação de N. Sem aplicação de N o rendimento de massa seca acumulada foi de apenas 1,64 t ha $^{-1}$; portanto, a aplicação de $\mathrm{N}$ na maior dose representou um aumento na produção de biomassa de $60 \%$ em comparação à testemunha sem aplicação do nutriente (Figura 2). Dessa forma, a produção de massa seca encontrada nesse experimento está de acordo com Côrrea Júnior et al. (1994), que citam a faixa de produção anual de massa seca acumulada da parte aérea de 1,5 a $3 \mathrm{t} \mathrm{ha}^{-1}$, para plantas fertilizadas com $5 \mathrm{~kg} \mathrm{~m}^{-2}$ de esterco de curral curtido.

Não houve mortalidade das plantas durante o período. As plantas não fertilizadas com nitrogênio apresentaram amarelecimento generalizado das folhas durante todo o ciclo de desenvolvimento. cortes realizados a cada $30 ; 42 ; 54$ ou 66 dias, em plantas cultivadas em condições de sombreamento parcial.

A maior produção de massa seca de plantas de Melissa officinalis cultivadas em condições de casa de vegetação, conforme pesquisa realizada por Blank et al (2005), pode demonstrar que a espécie estudada não suportou as condições de sombreamento impostas nessa pesquisa. Segundo Côrrea Júnior et al. (1994) essa espécie necessita alta incidência de luz para um bom desenvolvimento, apesar de suportar condições de sombreamento parcial.

A extração de óleo essencial da massa fresca das plantas de Melissa officinalis por arraste de vapor em aparelho tipo Clevenger modificado não foi eficiente, de forma que não foi possível detectar as diferenças entre os teores de óleo essencial contidos nas plantas dos diversos tratamentos. As destilações realizadas demonstraram rendimento de óleo essencial abaixo de $0,01 \%$.

Os resultados permitem concluir que o intervalo de cortes não afetou a produção de biomassa acumulada e doses elevadas de nitrogênio promoveram maiores produções de massa seca da parte aérea.

\section{REFERÊNCIAS} lada, o corte a cada 66 dias pode ser mais interessante do ponto de vista econômico, uma vez que, para o intervalo de cortes de 66 dias, foram feitos 4 operações de colheita ao longo do ano, enquanto que para o intervalo de cortes de 30 dias, 10 cortes foram realizados, aumentando o custo operacional de colheita da mesma quantidade produzida de massa seca acumulada.

Blank et al (2005), estudando a espécie em condições de casa de vegetação, obtiveram dois cortes por ciclo, não sendo possível o terceiro corte em razão da alta mortalidade de plantas. A produção encontrada pelos autores foi de 22,4 e 20,5 g planta $^{-1}$ de massa seca da planta toda, no primeiro e segundo corte, respectivamente, sendo o segundo corte realizado 77 dias após o primeiro, totalizando $42,9 \mathrm{~g} \mathrm{planta}^{-1}$ ciclo $^{-1}$. A produção de massa seca da planta toda por ciclo, observada pelos autores, foi portanto $45 \%$ superior ao encontrado nesse experimento $\left(23,7 \mathrm{~g} \mathrm{planta}^{-1}\right), \mathrm{com}$
BLANK AF; FONTES SM; OLIVEIRA AS; MENDONÇA MC; SILVA-MANN R; ARRIGONI-BLANK MF. 2005. Produção de mudas, altura e intervalo de corte em melissa. Horticultura Brasileira 3: 780-784.

CORRÊA JÚNIOR C; MING CL; SCHEFFER MC. 1994. Cultivo de plantas medicinais, condimentares e aromáticas. Jaboticabal/SP: FUNEP, 162p.

CZEPAK MP. 1995. Produção de óleo e mentol cristalizável em oito freqüências de colheita da menta (Mentha arvensis L.). Piracicaba: ESALQ. 81p. (Tese mestrado).

HERNÁNDEZ CML; FERRADÁ CAL; LUZ LA. 2001. Estúdios agrícolas em Melissa officinalis L. (toronjil): fecha de propagación e plantación. Rev. Cubana Plant. Med 3: 9397.

MAIA NB. 1998. Efeito da nutrição na qualidade do óleo essential da menta (Mentha arvensis L.) cultivada em solução nutritiva. In: MING LC; SCHEFFER MC; CORREA JUNIOR C; BARROS IBI; MATTOS JKA. (eds). Plantas medicinais, aromáticas e condimentares Avanços na Pesquisa Agronômica, BotucatuSP: UNESP-FCA 2, p. 81-95. 
MARTINS MC. 1993. Obtenção e avaliação de curcumina a partir de rizomas secos de cúrcuma (Curcuma longa L.), Campinas: UNICAMP. 176p. (Tese mestrado).

MONTANARI JUNIOR I. 1999. Aspectos do cultivo comercial da Melissa officinalis. Boletim Agroecológico 14: 18.
RAIJ B; ANDRADE JC; CANTARELLA H; QUAGGIO JA. 2001. Análise Química para avaliação da Fertilidade de Solos Tropicais. Campinas: Instituto Agronômico, 285p.

SARTÓRIO ML; TRINDADE C; RESENDE P; MACHADO JR. 2000. Cultivo orgânico de plantas medicinais. Viçosa/MG: Aprenda Fácil. 260p.
VOMEL A. 1984. Problems and advantages of mineral fertilization with medicinal plants. Acta Horticulturae 144: 115-121. 